\title{
Bachillerato en Turismo Ecológico y Licenciatura en Gestión Ecoturística de la Universidad de Costa Rica: Características sociodemográficas y ocupacionales de las personas graduadas
}

Bachelor's degree in Ecotourism and Licenciate Degree in Ecotourism Management at the University of Costa Rica: Sociodemographic and occupational characteristics of graduates

Anyerline Marín-Alfaro Luis Carlos Núñez-Masís

\section{Citar este documento según modelo APA}

Marín-Alfaro, Anyerline. y Núñez-Masís, Luis Carlos. (2020). Bachillerato en Turismo Ecológico y Licenciatura en Gestión Ecoturistica de la Universidad de Costa Rica: Características sociodemográficas y ocupacionales de las personas graduadas. Revista Actualidades Investigativas en Educación, 20(2), 1-30. Doi. 10.15517/aie.v20i2.41640 


\title{
Bachillerato en Turismo Ecológico y Licenciatura en Gestión Ecoturística de la Universidad de Costa Rica: Características sociodemográficas y ocupacionales de las personas graduadas
}

Bachelor's degree in Ecotourism and Licenciate Degree in Ecotourism Management at the University of Costa Rica: Sociodemographic and occupational characteristics of graduates

\section{Anyerline Marín-Alfaro ${ }^{1}$ Luis Carlos Núñez-Masís²}

\begin{abstract}
Resumen: El objetivo de la investigación fue identificar las características sociodemográficas y ocupacionales de las personas graduadas de la profesión de Turismo Ecológico de la Universidad de Costa Rica por medio de una encuesta, con el fin de fortalecer el accionar institucional en esta disciplina. La investigación tiene un enfoque cuantitativo y un alcance descriptivo. La población en estudio comprende 728 personas graduadas del Bachillerato en Turismo Ecológico y de la Licenciatura en Gestión Ecoturística, en todas las sedes donde se imparte la carrera, desde la primera graduación en 1995 hasta el año 2014. Se analizó una muestra de 251 personas graduadas, de tipo probabilística estratificada por sede y recinto donde se ha ofertado la carrera. La información se recolectó por medio de un cuestionario en línea, que se aplicó entre mayo y octubre de 2015. El artículo presenta las características de una población nunca analizada, por lo que es de interés histórico para la profesión. Entre los principales hallazgos se encontró que el 82,9\% de la población esta empleada y que un $12,4 \%$ se encuentran solo estudiando. El porcentaje de desempleo para estos profesionales es de 4,8\%. Las personas graduadas gozan de estabilidad laboral. Esta opción académica ha impactado de manera positiva las zonas más alejadas del país, en donde el turismo es un motor de desarrollo local. Debe ofrecerse en el corto plazo oportunidades para la obtención del grado de licenciatura, como una vía para enfrentar el subempleo y mejorar la inserción laboral.
\end{abstract}

Palabras clave: ocupación, empleo, ecoturismo, desarrollo local, educación superior

\begin{abstract}
It aims to identify sociodemographic and occupational characteristics of graduates of the Bachelor's degree in Ecotourism and Bachelor's Degree in Ecotourism Management at the University of Costa Rica. This research follows a quantitative approach and a descriptive scope. The population under study includes 728 graduates of the Eco-Tourism Bachelor and the Tourism Management Licentiate, since the first graduation in 1995 until the year 2014. A sample of 251 graduate people was analyzed, using a probability sampling, stratified by headquarter and branch. The information was collected through an online questionnaire which was applied between May and October 2015. The article presents the characteristics of a population never analyzed, so it is of historical interest for the profession. Among the main findings it was found that 82,9\% of the population is employed and a $12,4 \%$ is still studying, only. The unemployment percentage for these professionals is a $4,8 \%$. The graduated people have job stability. This academic option has had a positive impact on the most remote areas of the country, where tourism is an engine for local development. Opportunities must be offered in the short term for these students to obtain a licentiate's degree, as a way to face underemployment and improve job insertion.
\end{abstract}

Keywords: occupations, employment, ecotourism, local development, higher education

\footnotetext{
${ }^{1}$ Docente e investigadora de la Universidad de Costa Rica, del Bachillerato en Turismo Ecológico de la Sede de Occidente. Dirección electrónica: angerline.marin@ucr.ac.cr ORCID: http://orcid.org/0000-0003-2066-5504

2 Docente e investigador de la Universidad de Costa Rica, del Bachillerato en Turismo Ecológico del Recinto de Golfito. Dirección electrónica: luiscarlos.nunez@ucr.ac.cr ORCID: http://orcid.org/0000-0002-5260-1460
}

Artículo recibido: 21 de octubre, 2019

Enviado a corrección: 17 de febrero, 2020

Aprobado: 20 de abril, 2020 


\section{Introducción}

El desarrollo actual del turismo costarricense es el resultado de múltiples esfuerzos públicos y privados a lo largo de varias décadas. De acuerdo con Quesada (2006) y el Instituto Costarricense de Turismo (ICT), esta actividad experimentó un auge en Costa Rica a partir de 1987, y desde ahí, los indicadores del turismo continuaron mostrando un ritmo de crecimiento constante y acelerado (Instituto Costarricense de Turismo [ICT], 2002). Como respuesta a las necesidades del desarrollo turístico de la época, en 1991, la Universidad de Costa Rica (UCR) creó el Bachillerato en Turismo Ecológico en la Sede de Guanacaste (Universidad de Costa Rica [UCR], 1991), y desde 1998 se empieza a ofertar en otras sedes y recintos. A la fecha, la carrera se imparte en 5 unidades académicas. La institución realizó una labor pionera al ser la primera universidad pública en ofrecer una carrera en esta área (Arrieta y Rivera, 2006).

Años después, en la labor por fortalecer y actualizar la oferta académica en Turismo Ecológico en la UCR, se observó un incremento en la cantidad de universidades e institutos que ofertan especialidades en turismo y en hotelería, las cuales aunque en la mayoría de los casos son poco afines al turismo ecológico, han venido a incrementar la competencia de profesionales en el mercado laboral (Gutiérrez, Kikut, Corrales y Picado, 2018). Aunado a ello, debe mencionarse que el país no cuenta con un colegio de profesionales en turismo, aspecto que propicia competencia en el mercado laboral, pero sin regulación alguna.

Ante esta falencia y un creciente sector turístico (Organización Mundial del Turismo, [OMT], 2019), la educación superior en Costa Rica tiene importantes retos relacionados con el aseguramiento de la calidad y el aumento de la cobertura en la formación de futuros profesionales en turismo (Programa del Estado de la Nación [PEN], 2015). En este contexto, la carrera de Turismo Ecológico inició un proceso de autoevaluación y posteriormente elaboró un plan de mejoramiento, antecedentes que hacen al equipo investigador plantearse la siguiente pregunta de investigación: ¿Cuáles son las características sociodemográficas y ocupacionales de las personas graduadas de la carrera de Turismo Ecológico de la UCR entre 1995 y 2014 ?

Por lo tanto, es propósito de esta investigación, identificar las características sociodemográficas y ocupacionales de las personas graduadas de la profesión de Turismo Ecológico de la Universidad de Costa Rica por medio de una encuesta, con el fin de fortalecer el accionar institucional en esta disciplina. 
Si bien es cierto, Gutiérrez, Kikut, Corrales, y Picado (2018) realizaron una investigación sobre las personas graduadas de turismo, esta no distingue la institución de procedencia. Lo anterior, destaca la importancia de la presente investigación, ya que nunca se ha estudiado la población en análisis. Así, los resultados obtenidos proporcionan datos específicos y únicos para la población graduada de la carrera de Turismo Ecológico de las sedes regionales de la UCR desde su primera generación hasta el año 2014, datos interés histórico para la profesión.

Este artículo es el segundo que surge del proyecto de investigación Analizar las condiciones del mercado laboral de las personas graduadas de la carrera de Turismo Ecológico de la Universidad de Costa Rica como mecanismo para fortalecer el accionar institucional en esta disciplina, realizado entre docentes del Recinto de Golfito y la Sede de Occidente, Recinto de Grecia, en el periodo 2015 - 2016. El primer artículo se titula La profesión de Turismo Ecológico en la Universidad de Costa Rica: Un análisis desde la perspectiva de su población graduada (Núñez y Marín, 2018), y presenta la opinión de este conjunto de personas acerca de su perfil profesional. Entre los principales resultados destacan: mejorar el perfil profesional con un mejor manejo de idiomas, en especial el inglés, y un mayor número de experiencias prácticas dentro de su formación.

\section{Referente teórico}

La llegada del siglo XXI marcó importantes retos para la humanidad, estos fueron materializados en el año 2000 cuando se adquirió el compromiso de liberar a nuestros semejantes, hombres, mujeres, niños y niñas de condiciones deshumanizadoras, tales como la pobreza extrema (Organización de las Naciones Unidas [ONU], 2015). Según la misma ONU (2015), para alcanzar dicho reto, se lanzaron los objetivos del milenio, entre los cuales se cita el erradicar la pobreza extrema y el hambre, y garantizar la sostenibilidad del medio ambiente. Estos objetivos se convierten en referentes universales y reafirman la pertinencia de continuar mejorando la labor académica en la carrera de Bachillerato en Turismo Ecológico, campo del saber que impulsa el desarrollo sostenible en Costa Rica.

El Turismo Ecológico se relaciona con el concepto de desarrollo humano, el cual, según el Programa de las Naciones Unidas para el Desarrollo (2015), se entiende como la creación de capacidades humanas mediante la mejora de sus vidas, a través de una participación activa; es decir, se trata de un enfoque más amplio que incluye los recursos humanos, las necesidades básicas y el bienestar de la población. 
La educación superior es clave para el desarrollo humano y el crecimiento económico, por lo que resulta ineludible un análisis del vínculo entre las universidades y el sector empleador, los programas de estudio deben incorporar elementos que permitan la formación de mejores ciudadanos, así como que brinden conocimientos y habilidades necesarias para que las personas profesionales respondan al sector laboral, esto muchas veces puede significar una revolución en la academia , quienes han dirigido sus esfuerzos a la formación de profesionales, no a su empleabilidad y desempeño laboral (García y Cárdenas, 2018).

En el contexto actual, las personas jóvenes combinan trabajo y estudios superiores, esto sucede porque las empresas valoran la experiencia, existen trabajos eventuales, una búsqueda de flexibilización y autonomía financiera (Busso y Pérez, 2015). En esta misma línea, Papalia, Feldman y Martorell (2012) coinciden en que la educación superior incrementa las oportunidades de empleo y el poder adquisitivo de los individuos, de manera que muchos optan por combinar la universidad y el trabajo, y regresar a los estudios una vez que han iniciado la etapa laboral.

Estos autores hacen referencia en que combinar el trabajo con el estudio puede repercutir de manera favorable en la madurez y en el manejo de la vida de las personas, pero puede traer efectos negativos en alcanzar las metas de estudio, en especial a nivel de posgrado (Papalia et al., 2012). Asimismo, para Busso y Pérez (2015), la posibilidad de combinar trabajo y estudio parece estar condicionada por el tipo de empleo, la intensidad, la duración horaria, la naturaleza de la función ejercida y el esfuerzo físico que supone, entre otras. En la visión de estos autores, trabajar mientras se están realizando estudios superiores puede obligar a los jóvenes a reducir el tiempo dedicado al estudio, y de esa manera, aumentar el riesgo de retraso y fracaso en su formación (Busso y Pérez, 2015).

Como parte de sus funciones, las instituciones de educación superior en Costa Rica deben prestar mayor atención al proceso de transición entre la etapa de aprendizaje universitario y el paso a la vida laboral que afrontan las personas graduadas. Se hacen necesarios procesos de retroalimentación en los que se puedan identificar las expectativas de las personas recién graduadas y las necesidades de los diversos grupos empleadores, esto con la finalidad de definir estrategias de inserción laboral y mantener una adecuada actualización de los planes de estudio (García y Cárdenas, 2018; Papalia et al., 2012).

En cuanto a las personas graduadas de la educación superior en Costa Rica, para Gutiérrez, Kikut, Navarro, Azofeifa y Rodríguez (2015), al culminar la educación universitaria son dotadas de actitudes, conocimientos y habilidades específicas de una determinada 
disciplina, lo que les permite tener mayores competencias para desempeñarse en el mercado laboral; por lo tanto, deberían de gozar de menores tasas de desempleo y de mejores condiciones laborales. No obstante, cuando se analiza la población económicamente activa debe considerarse que las personas que se dedican de manera exclusiva a estudiar, las que no tienen la edad para laborar (según la legislación de cada país), las pensionadas y las que realizan trabajos no remunerados quedan excluidas de este concepto (Mankiw, 2014).

Asimismo, Samuelson y Nordhaus (2014), para referirse a la composición de la población económicamente activa, incorporan el concepto de tasa de participación de la fuerza laboral, el cual definen como la proporción entre los que integran la fuerza laboral y la totalidad de la población que tiene 16 o más años. Igualmente, definen dos tipos de desempleo: el estructural y el temporal. El primero se da cuando existen puestos de trabajo vacantes, pero los trabajadores no tienen las competencias para ocuparlos, o bien se encuentran en regiones geográficas distintas (Samuelson y Nordhaus, 2014). El segundo tipo incluye a las personas que están desempleadas porque recién se incorporan a la población activa y las que ya cuentan con experiencia, pero están desempleadas mientras encuentran una nueva oportunidad.

Según la visión de los autores de esta investigación, el empleo en turismo desarrollado en el país tiene particularidades que lo pueden diferenciar de otras actividades; por ejemplo, la capacidad para trabajar en zonas alejadas de los principales centros urbanos en horarios no tradicionales, la necesidad de establecer relaciones con personas de diversas nacionalidades en ambientes vacacionales, los constantes desplazamientos a diversas regiones turísticas del país y el trabajo por temporadas, entre otras.

En cuanto al ordenamiento territorial de producto turístico, el ICT (2012) estableció que el espacio geográfico costarricense está dividido en unidades de planeamiento turístico, las cuales son definidas como una "división territorial de todo el espacio turístico del país que agrupa características particulares que en su conjunto forman la imagen turística del destino" (p.24). De este modo, se han identificado siete unidades de planeamiento; a saber, Valle Central, Guanacaste, Llanuras del Norte, Pacífico Medio, Puntarenas, Caribe y el Pacífico Sur. Las empresas turísticas en Costa Rica están distribuidas en todas las unidades de planeamiento turístico, sin embargo, por las características propias del modelo de desarrollo nacional, las empresas se encuentran concentradas principalmente en el Valle Central y en Guanacaste (ICT, 2015). 
El sector turismo costarricense es regulado mediante el Reglamento de Empresas y Actividades Turísticas (2013), el cual establece que estas principalmente se clasifican en agencias de viajes, hospedajes, restaurantes, arrendadoras de vehículos, transporte marítimo, transporte aéreo y actividades temáticas. Esta categorización permite identificar un segmento importante del conjunto de organizaciones empleadoras de profesionales universitarios; sin embargo, es evidente que el sector público dedicado a la educación y a la conservación, así como, las organizaciones no gubernamentales amparadas en la Ley de Asociaciones $\mathrm{N}^{\circ} 218$, también son gremios empleadores de la persona profesional en Turismo Ecológico.

\section{Metodología}

Este trabajo forma parte de los resultados del proyecto de investigación: Análisis de la condición laboral de las personas graduadas de la carrera de Turismo Ecológico de la Universidad de Costa Rica, y este articulo constituye la segunda publicación acerca de sus resultados.

\subsection{Enfoque}

Para lograr cumplir con el objetivo general de esta investigación se abordó un enfoque cuantitativo, con un alcance descriptivo y un diseño no experimental transversal (Hernández, Fernández y Baptista, 2014).

\subsection{Unidades de análisis}

La población estudiada comprende $(M) 728$ personas graduadas del Bachillerato en Turismo Ecológico y la Licenciatura en Gestión Ecoturística, en el periodo de 1995 (primera generación de personas graduadas) a 2014, de las sedes universitarias de Guanacaste, Caribe, Pacífico y Atlántico, así como de los recintos universitarios de Paraíso, Golfito y Grecia. La identificación de estas personas se realizó por medio de los datos disponibles en el Sistema de Aplicaciones Estudiantiles (SAE) (UCR, 2015). Aquellas personas que obtuvieron ambos diplomas fueron contabilizadas en una única ocasión. Con ello se evitó el riesgo de que fueran seleccionadas dos veces.

Posteriormente, se construyó una base de datos inicial y luego se realizó un muestreo de tipo probabilístico estratificado que consideró cada conjunto de personas graduadas de sede o recinto como un estrato. Para la definición de la muestra ( $n)$, se utilizó el software 
Launch Stats 2.0 y se fijó un margen de error del 5\% con un nivel de confianza del 95\% y un porcentaje máximo de varianza del $50 \%$. Finalmente, se procedió a enumerar a las personas de cada estrato y a seleccionar a las personas participantes de forma aleatoria. La Tabla 1 presenta el tamaño de la muestra seleccionada según la composición de la población en cada sede o recinto.

Debe señalarse que, en caso de que no se lograra contactar a alguna de las personas seleccionadas, se realizó una nueva selección aleatoria entre el resto de las personas que no fueron escogidas al inicio. Este ejercicio debió realizarse en tres ocasiones para recolectar la información solicitada a cada persona participante. En este sentido, para que las personas participantes ingresaran a dicha plataforma se les contactó mediante correo electrónico. La dirección de correo electrónico de cada participante se localizó por varias fuentes: el SAE, las redes sociales y llamadas telefónicas.

Tabla 1

Determinación del tamaño de la muestra probabilística, estratificada por sede y recinto donde se imparte la carrera, UCR - Costa Rica (2015)

\begin{tabular}{lrr}
\hline \multicolumn{1}{c}{ Sede o Recinto } & Población $(\boldsymbol{N})$ & Muestra $(\boldsymbol{n})$ \\
\hline Sede de Guanacaste & 314 & 108 \\
Sede del Caribe & 149 & 52 \\
Sede de Puntarenas & 117 & 40 \\
Sede del Atlántico (Recinto de Turrialba) & 46 & 16 \\
Sede del Atlántico (Recinto de Paraíso) & 58 & 20 \\
Recinto Golfito & 30 & 10 \\
Recinto de Grecia & 14 & 5 \\
Total & $\mathbf{7 2 8}$ & $\mathbf{2 5 1}$ \\
\hline
\end{tabular}

Fuente: Elaboración propia, con información de los datos del SAE de la UCR, 2015.

\subsection{Técnicas de recolección de datos}

Para la recolección de los datos se utilizó la técnica de encuesta, el instrumento fue evaluado mediante juicio de expertos y validado por un grupo de 10 personas graduadas de 3 recintos universitarios diferentes. El instrumento incluyó preguntas cerradas, escalas de calificación numeradas de 1 a 5 (siendo 5 la mejor) y preguntas abiertas. En la parte inicial, se solicitó un consentimiento informado, luego se brindaron las instrucciones para completar la información solicitada. En caso de que alguna información suministrada no tuviese el formato solicitado, la plataforma permitió generar alertas al usuario que imposibilitara su envío a cabalidad hasta tanto no se corrigiera.

El instrumento agrupó 29 ítems según las siguientes variables: características sociodemográficas, estudios académicos y ocupación. En el estudio de Núñez y Marín 
(2018), se utilizaron los ítems relativos a la percepción de las personas graduadas sobre su formación, y en este artículo, específicamente, se incluyeron otras variables que responden a los aspectos sociodemográficos, estudios académicos y de ocupación, según se muestra en el Anexo 1.

La recolección de datos se extendió por un periodo de cinco meses entre mayo y octubre de 2015. En este tiempo, se enviaron recordatorios electrónicos bisemanales a las personas seleccionadas que no hubiesen participado hasta ese momento, lo que permitió alcanzar las (n) 251 encuestas de las personas incluidas en la muestra.

También se realizó la técnica de revisión documental con el fin de contrastar los datos obtenidos con otras investigaciones relacionadas con el objeto de estudio. Se sistematizó e integró la revisión documental con el procesamiento y análisis de esos datos e información, lo cual buscó la rigurosidad académica y científica.

\subsection{Procesamiento de análisis}

Dado que se definió un alcance descriptivo que no intentaba pronosticar un dato, no se planteó una hipótesis (Hernández et al. 2014). Se generó una hoja de cálculo que permitió establecer categorías por cada variable. Seguidamente, se procedió a explorar los datos obtenidos en la recolección, y se analizaron descriptivamente por separado. Finalmente, se realizó una interpretación de los datos mediante tablas y gráficos de barras y radial.

\section{Resultados}

\subsection{Características sociodemográficas de la población graduada de la Carrera de Turismo de la UCR}

En la Tabla 2 se muestran las características sociodemográficas que definen a la población graduada en el periodo comprendido entre 1995 y 2014 de la carrera de Bachillerato en Turismo Ecológico y Licenciatura en Gestión Ecoturística en todas las sedes universitarias de la UCR. 
Tabla 2

Características sociodemográficas de la población graduada entre los años 1995 y 2014 según sede o recinto, UCR - Costa Rica $(n=251)$

(valores nominales y porcentuales)

\begin{tabular}{|c|c|c|c|c|c|c|c|c|}
\hline Indicador & Guanacaste & Caribe & Puntarenas & Turrialba & Paraíso & Golfito & Grecia & Total \\
\hline $\begin{array}{l}\text { Población } \\
\text { graduada * }\end{array}$ & 314 & 149 & 117 & 46 & 58 & 30 & 14 & 728 \\
\hline Hombres (\%) * & 44,6 & 38,9 & 40,2 & 34,8 & 36,2 & 40 & 57,1 & 41,5 \\
\hline Mujeres (\%) * & 55,4 & 61,1 & 59,8 & 65,2 & 63,8 & 60 & 42,9 & 58,5 \\
\hline \multicolumn{9}{|l|}{ Rango de edad } \\
\hline $\begin{array}{l}\text { Entre } 22 \text { y } 25 \text { años } \\
(\%)\end{array}$ & 12 & 13,5 & 52,5 & 0 & 45 & 70 & 80 & 24,7 \\
\hline $\begin{array}{l}\text { Entre } 26 \text { y } 30 \text { años } \\
(\%)\end{array}$ & 44,4 & 50 & 47,5 & 25 & 55 & 20 & 20 & 43,8 \\
\hline $\begin{array}{l}\text { Entre } 31 \text { y } 40 \text { años } \\
(\%)\end{array}$ & 29,6 & 34,6 & 0 & 75 & 0 & 10 & 0 & 25,1 \\
\hline $\begin{array}{l}\text { Entre } 41 \quad 0 \text { más } \\
\text { años (\%) }\end{array}$ & 13,9 & 1,9 & 0 & 0 & 0 & 0 & 0 & 6,4 \\
\hline \multicolumn{9}{|l|}{ Estado civil } \\
\hline Soltero (\%) & 49,1 & 65,4 & 90 & 43,8 & 90 & 70 & 90 & 63,4 \\
\hline Casado (\%) & 24,1 & 13,5 & 7,5 & 37,5 & 0 & 20 & 0 & 17,5 \\
\hline Unión libre (\%) & 22,2 & 21,2 & 2,5 & 18,8 & 10 & 10 & 10 & 17,1 \\
\hline Divorciado (\%) & 4,6 & 0 & 0 & 0 & 0 & 0 & 0 & 2 \\
\hline $\begin{array}{ll}\text { Lugar } & \text { de } \\
\text { residencia } & \end{array}$ & & & & & & & & \\
\hline Valle Central (\%) & 19,4 & 44,2 & 50 & 68,8 & 70 & 10 & 100 & 37,9 \\
\hline Chorotega (\%) & 62 & 5,8 & 5 & 6,3 & 10 & 10 & 0 & 30,3 \\
\hline $\begin{array}{l}\text { Pacífico Central } \\
(\%)\end{array}$ & 6,5 & 3,9 & 27,5 & 6,3 & 10 & 0 & 0 & 9,2 \\
\hline Huetar Caribe (\%) & 0 & 38,5 & 0 & 0 & 0 & 0 & 0 & 8 \\
\hline Huetar Norte (\%) & 8,3 & 1,9 & 12,5 & 6,3 & 10 & 10 & 0 & 7,6 \\
\hline Brunca (\%) & 3,7 & 3,9 & 5 & 6,3 & 0 & 70 & 0 & 6,4 \\
\hline Fuera del país (\%) & 0 & 1,9 & 0 & 6,3 & 0 & 0 & 0 & 0,8 \\
\hline \multicolumn{9}{|l|}{$\begin{array}{l}\text { Grado académico } \\
\text { superior }\end{array}$} \\
\hline Bachillerato (\%) & 61,1 & 55,8 & 80 & 62,5 & 80 & 60 & 100 & 65,3 \\
\hline Licenciatura (\%) & 27,8 & 25 & 10 & 18,8 & 10 & 40 & 0 & 22,3 \\
\hline Maestría (\%) & 11,1 & 19,2 & 10 & 18,8 & 10 & 0 & 0 & 12,4 \\
\hline Doctorado (\%) & 0 & 0 & 0 & 0 & 0 & 0 & 0 & 0 \\
\hline
\end{tabular}

Fuente. Elaboración propia, con información del SAE, 2016.

Según muestra la Tabla 2, en la población graduada predominan las mujeres, quienes representan un 58,5\%, al contrario los varones comprenden el $41,5 \%$ de la población analizada. La prevalencia de mujeres se convierte en una tendencia en cada una de las 
unidades académicas participantes en el estudio, a excepción del Recinto de Grecia en donde el porcentaje de varones es de $57,1 \%$.

La Tabla 2 también muestra la edad en grupos etarios, al respecto la mayoría de las personas encuestadas $(43,8 \%)$ se ubica entre los 26 y 30 años, mientras los más jóvenes, cuya edad oscila entre los 22 y 25 alcanzan aproximadamente el $24,7 \%$ de la muestra, y se ubican mayormente en los recintos de Golfito y de Grecia; mientras tanto, en las Sedes de Guanacaste y del Caribe, hay personas graduadas con más de 40 años y representan el $6,4 \%$ de la población en estudio.

La Tabla 2 también evidencia una mayoría de personas solteras en la carrera (más del 63,4\%), estas viven en el Valle Central del país (alrededor del 37,9\%). Sin embargo, es importante hacer notar que, en la mayoría de los casos, las personas graduadas tienden a residir en el lugar donde realizaron sus estudios. Así, por ejemplo, de toda la población graduada en la carrera durante 25 años, más del 30,3\% vive en la región Chorotega, mientras que el resto de las regiones alejadas del Valle Central apenas hospedan a un $31,1 \%$ del conjunto de profesionales si se considera que menos del $0,8 \%$ reside fuera del país.

En cuanto al mayor grado académico alcanzado durante el periodo de estudio, más del $65,3 \%$ de las personas encuestadas cuenta únicamente con el bachillerato universitario, mientras que apenas el $22,3 \%$ tiene el grado de licenciatura; mientras tanto, el grado de maestría solo lo ha alcanzado el $12,4 \%$ de la población, y no hay registro de personas graduadas con el grado de doctorado.

Al analizar los resultados obtenidos, debe mencionarse que, según el Observatorio Laboral de Profesionales (OLAP), más del 61\% de las personas graduadas universitarias son mujeres (Gutiérrez, Kikut, Corrales, y Picado, 2018). Por su parte, para el Programa Estado de la Nación (PEN), las mujeres representan el 50,4\% de los nuevos ingresos a carrera en la UCR (PEN, 2017). Ambos datos coinciden con la predominancia de féminas encontrada en el presente estudio.

En el mismo PEN (2017), se determinó que la población femenina que cursa estudios superiores enfrenta desafíos en temas de empleabilidad, los cuales tienen que ver con una participación laboral baja, en especial cuando se trata de puestos de dirección; es decir, la experiencia que adquieren las mujeres no se capitaliza en ingresos, y solo un $10 \%$ de esta población, con un nivel de posgrado, acceden a puestos de dirección o gerencia. Sin embargo, a nivel mundial cada vez es mayor la proporción de mujeres que desea adquirir 
conocimientos académicos superiores al bachillerato, esto en comparación con los hombres (Papalia et al., 2012).

En los resultados se indicó que la mayor parte de la población en estudio se encuentra entre los 22 y 30 años, y que la mayoría de las personas graduadas son solteras. Estos datos coinciden con lo que señalan Gutiérrez et al. (2015) para quienes las personas graduadas del área de turismo de las universidades costarricenses se distribuyen en las siguientes categorías: un $71 \%$ son solteros, un 20 son casados, un $8 \%$ viven en unión libre, mientras que alrededor del $1 \%$ de estas personas son viudos o divorciados.

Asimismo, Papalia et al. (2012), coinciden en que la educación superior incrementa las oportunidades de empleo, así como el poder adquisitivo de las personas, por lo que esta población ya cuenta con herramientas de formación que facilitarán su progreso social. También, se desprende del análisis que las condiciones laborales tienden a variar en función el periodo de vida que atraviesan las personas, desde el momento en que culminan sus estudios universitarios hasta alcanzar una adultez más consolidada, con ello mayor experiencia y más posibilidades de obtener un mejor trabajo.

El hecho de que, en conjunto, la mayor parte de población graduada de Turismo Ecológico resida fuera del Valle Central se considera un aspecto positivo, ya que en Costa Rica las regiones fuera de la gran área metropolitana son las que presentan mayor porcentaje de personas en condiciones de pobreza extrema, en especial cuando se consideran las regiones Brunca y Huetar Caribe, con porcentajes de la población de 13,7\% y un $11,1 \%$ respectivamente, que viven en pobreza extrema (PEN, 2016a).

La carrera contribuye a sopesar esta diferencia formando profesionales en las regiones que más los necesitan. Es importante indicar que el Índice de Progreso Social (IPS), en centros turísticos, revela información con respecto a la relación turismo y el progreso social de las comunidades (ICT, 2016). Según el ICT (2016), de diez sitios analizados solo tres superan el IPS turístico en al menos un 75\% (La Fortuna, San Carlos, Dota, los Santos, Monteverde y Puntarenas), los demás están por debajo de esa calificación (ICT, 2016; Porter, Stern y Green, 2017).

La elevada proporción de profesionales con grado de bachillerato universitario (65\%) y de los cuales menos de una tercera parte continúa estudiando a nivel de licenciatura o posgrado, coincide con la visión de Angulo, Quejada y Yánez (2014), quienes señalan que las personas graduadas en educación superior en turismo se concentran en el nivel de 
pregrado y resaltan la necesidad de trascender hacia estudios superiores debido a las exigencias del contexto general y la evolución del mercado.

En otra investigación reciente, Gutiérrez et al. (2015) indican que, en Costa Rica, de las personas graduadas en educación superior, el $4 \%$ se mantienen con un bachillerato universitario después de tres años de graduarse, mientras que más del $78 \%$ alcanzan el nivel de licenciatura, y un 12,4\% logran un nivel de posgrado. Sin embargo, esta situación afecta en mayor grado a las personas graduadas del área de turismo, en comparación con la situación general del país para quienes alcanzan un grado universitario.

Lo anterior, también se condiciona a partir del hecho de que, en la UCR, la Licenciatura en Gestión Ecoturística cuenta con 10 años de haberse creado en la Sede Universitaria de Guanacaste, pero es hasta el 2016 que se oferta por primera vez en el Recinto de Golfito y en la Sede Universitaria del Caribe (Comisión de Autoevaluación de Turismo Ecológico, 2013). Debe aunarse el hecho de que en la actualidad la institución solo oferta una maestría en Gestión Ambiental y Ecoturismo, creada en el año 2003 (OPES-07-2003), que se imparte únicamente en la Sede Rodrigo Facio. Lo que ha representado un inconveniente para el conjunto de profesionales del Bachillerato en Turismo Ecológico de regiones alejadas de San José por el desplazamiento, y por el costo económico que una maestría representa.

\subsection{Situación ocupacional de las personas graduadas}

La Figura 1 muestra la situación ocupacional de las personas graduadas del Bachillerato en Turismo Ecológico y la Licenciatura en Gestión Ecoturística, clasificadas por grupos según tres condiciones ocupacionales: las personas que trabajaban, las que únicamente estudian y las que no estudian ni trabajaban al momento de aplicar la encuesta. 


\section{Figura 1}

\section{Situación ocupacional de las personas graduadas del Bachillerato en Turismo Ecológico y la Licenciatura en Gestión Ecoturística, clasificadas por grupos según tres condiciones ocupacionales, UCR - Costa Rica $(n=251)$}

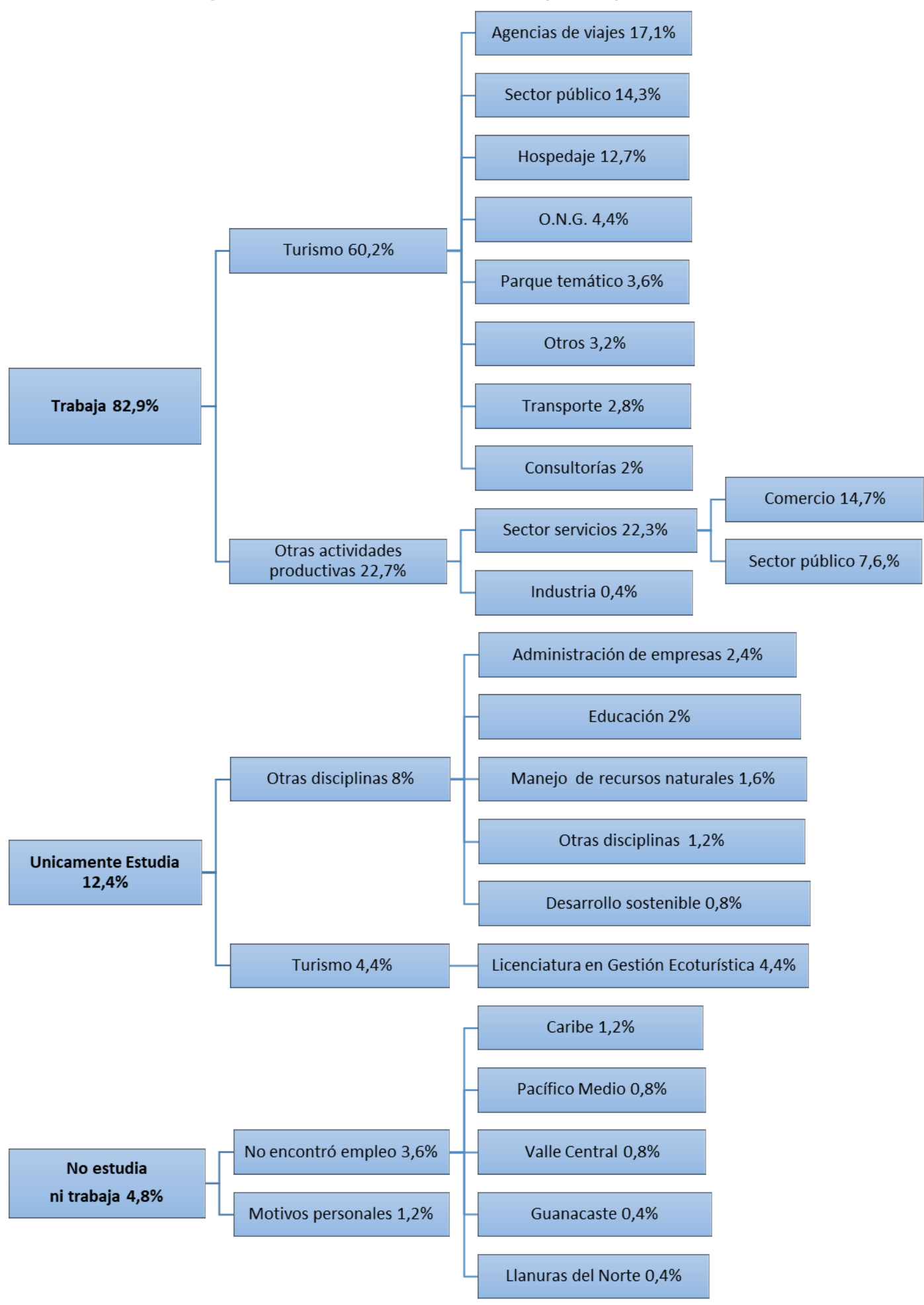


Fuente: Elaboración propia, con información de los datos reunidos en la encuesta, 2016.

A partir de la Figura 1, se evidencia que el 82,9\% de las personas graduadas trabaja, y que la mayoría $(60,2 \%)$ se desempeña en el sector turismo. Es importante señalar que más del $44,2 \%$ de quienes trabajan se distribuyen en tres actividades principales de acuerdo con las necesidades de las organizaciones empleadoras; a saber, en agencias de viajes o tour operadoras $(17,1 \%)$, en instituciones públicas cuyas actividades se relacionan con el turismo (más del 14,3\%) y en el sector de hospedaje (12,7\%).

De igual manera, la Figura 1 muestra que alrededor del 22,7\% de este capital humano, se desempeña en el sector industrial o en otras actividades del sector servicios. El colectivo que únicamente estudia representa más del 12,4\%, de los cuales un 4,4\% están llevando la Licenciatura en Gestión Ecoturística de la Sede de Guanacaste. Mientras que el 8,0\% está enfocado en especialidades relacionadas con el turismo, como el manejo de recursos naturales y el desarrollo sostenible, entre otras. Otro de los hallazgos relevantes es que la Región Caribe es donde reside el mayor número de personas que manifiesta no estudiar ni trabajar. Algunos de los principales argumentos para no continuar estudiando o incorporarse a la fuerza laboral son los motivos personales o no encontrar empleo.

Según el Observatorio Laboral de Profesiones de CONARE, las personas graduadas en turismo, provenientes de diferentes universidades públicas y privadas, indica, que el 92\% de profesionales de esta área cuenta con empleo (Gutiérrez et al. 2015); no obstante, en la presente investigación se determinó que la participación laboral del conjunto de personas graduadas de turismo ecológico es de un $82,9 \%$, cifra que se cataloga como favorable, porque muestra que, a pesar de que la mayoría de estas personas disponen solo del bachillerato como grado académico superior, han logrado insertarse al mundo laboral. Sin embargo, es un llamado de atención para que la institución mejore su vínculo con la población graduada, el sector empleador, y mantenga actualizado su plan de estudios.

Es necesario considerar que el turismo es una categoría importante del comercio internacional de servicios (OMT, 2016), por lo que los sectores que emplea son tan variados como las mismas necesidades humanas. No obstante, en la presente investigación se muestra que en Costa Rica las personas que trabajan en turismo se concentran en tres actividades mayoritarias: las agencias de viajes o turísticas, las empresas públicas y el sector hospedaje.

Analizando las agencias de viajes como el principal gremio empleador de la población en estudio, se debe resaltar que, según Rodríguez Cid, Fraiz Brea y Ramos Valcárcel (2015 
producto de las nuevas formas de comercialización de los servicios turísticos hay un conjunto importante de estas empresas que han cerrado sus negocios y la situación ha obligado a otras a cambiar sus herramientas tradicionales de mercadeo para implementar nuevos y mejorados métodos de comercialización y promoción turística, basados en las Tecnologías de la Información y la Comunicación (TIC). Cambios recientes en el uso de las TIC se evidencian en el mercado de los viajes. Para Cid et al. (2015), en este sector, las empresas turísticas crean canales de comercialización directos con el cliente, así evitan negociar con intermediarios con el propósito de mejorar la eficiencia y favorecer la reducción de costos.

También es importante indicar que una parte de la fuerza laboral en el mundo se desempeña en el sector público (Navarro y Selman, 2014), realidad que coincide con la satisfacción que sienten el conjunto de profesionales en turismo contratados en el sector gubernamental. Los mismos autores, citando a la Organización para la Cooperación y el Desarrollo Económico (2011), indican que en países como Noruega y Dinamarca el empleo público representa el 30\%, en los Estados Unidos de América el 16\% y en América Latina representa aproximadamente el 15\%. En esta misma línea, Cerda (2016) señala que en algunos países existe una diferencia importante a favor de las remuneraciones del sector público, aunque esta es solo una dimensión de los múltiples beneficios que se pueden sumar, como el derecho a mayor cantidad de días de vacaciones y la rotación en los cargos, entre otros.

De acuerdo con el Instituto Nacional de Estadística y Censos (INEC) (2016), cada trimestre entre los años 2013 y 2015 el turismo empleó, en promedio, a 150548 personas, quienes fueron ocupados en el sector de alimentos y bebidas, seguido por hospedaje. Asimismo, en el año 2014, el sector agencias de viajes empleó en promedio a 14985 personas (INEC, 2016). Sin embargo, presentó variaciones porcentuales trimestrales severas relacionadas con la generación de empleo, que afectaron a un grupo importante de costarricenses, en especial cuando se comparan las temporadas altas y bajas, según la cantidad de turistas que se mueven a nivel nacional e internacional.

En la población de personas graduadas de la carrera de Turismo Ecológico hay 2 grupos mayoritarios, los cuales son: las personas jóvenes y las mujeres, estos conjuntos de poblaciones fueron analizados por el PEN (2016b) quien determinó que ambos grupos presentaban condiciones precarias de empleabilidad en el país; por ejemplo: la tasa de desempleo para jóvenes fue de 19,7\% y la participación laboral de las personas menores de 25 años ha decrecido desde el año 2006 (PEN, 2018), y para las mujeres alcanzó un 14,9\% 
(INEC, 2019), por lo que la tasa de desempleo identificada para la población en estudio (5\%) se considera baja.

Gutiérrez et al. (2015) ubican a la carrera de turismo en Costa Rica como parte de las ciencias sociales, en donde, en términos generales el desempleo para las personas profesionales pertenecientes a esta profesión y que se graduaron entre los años 2008 y 2010 alcanzó el 8,03\%. Sin embargo, esta tasa de desempleo resulta baja si se compara con el promedio nacional que, desde el año 2015, se ha mantenido en niveles cercanos al $9 \%$ (INEC, 2017) y para el año 2018 alcanzó el 12\% (INEC, 2019).

Es importante señalar que valores extremos se registran para carreras con el menor desempleo, a saber, archivística, que no registró profesionales desempleados, y producción audiovisual, que apenas supera el $1 \%$ de personas desocupadas. En el otro extremo, carreras como trabajo social y antropología registran porcentajes de desempleo de $18,28 \%$ y $15,91 \%$ respectivamente. Se evidencia que el obtener un título universitario no es necesariamente una garantía para encontrar empleo, y que las posibilidades decrecen cuando las personas se conforman con un nivel de bachillerato universitario (Gutiérrez et al., 2015).

La distribución de profesionales que laboran en el área de turismo, según unidad de planeamiento se muestra en la Figura 2. El 68,4\% de las personas se ubican en Guanacaste y el Valle Central; mientras que el Pacífico Sur, Las Llanuras del Norte y del Caribe costarricense requieren de una asistencia intermedia en profesionales del área. En el otro extremo, dos unidades cercanas como el Pacífico Medio y Puntarenas requieren la menor asistencia de profesionales en turismo. 
Figura 2

Porcentaje de personas graduadas que laboran en turismo según unidad de planeamiento del ICT, UCR-Costa Rica, 2016 ( $n=251)$

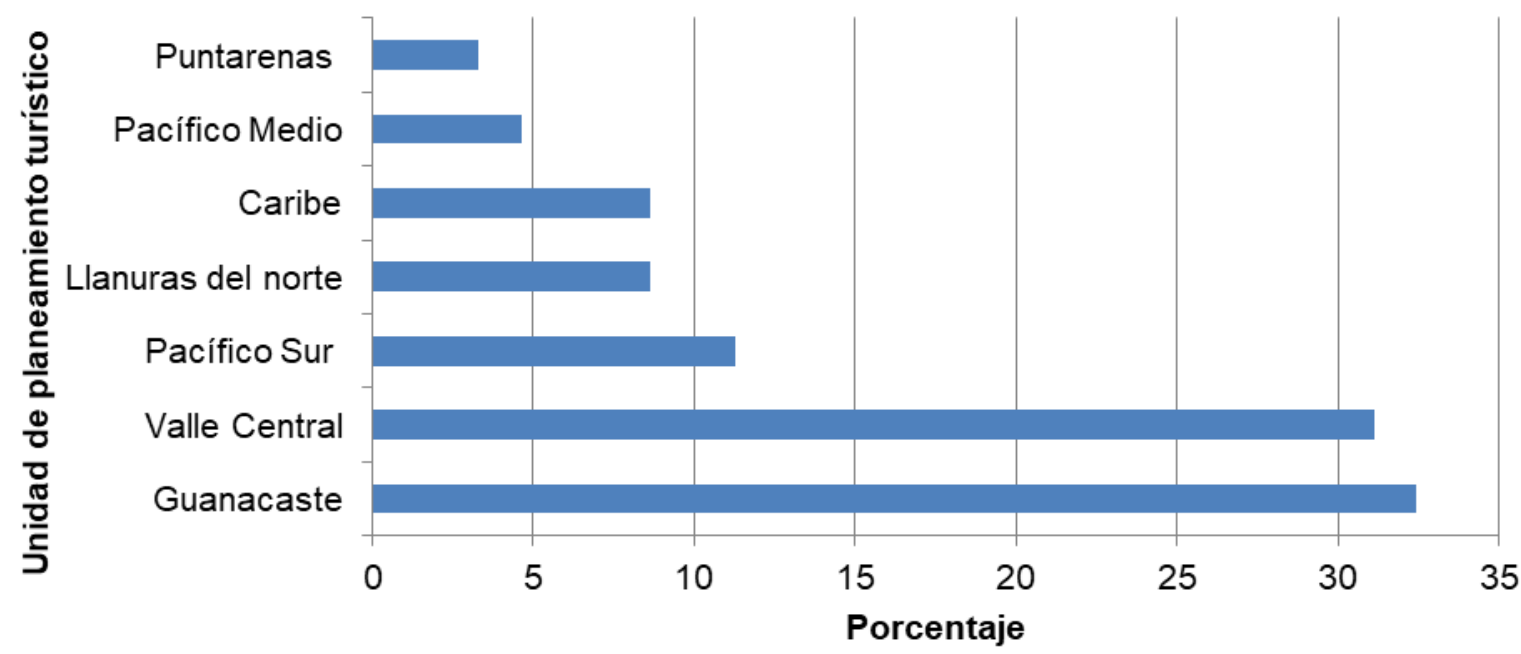

Fuente: Elaboración propia, con información de los datos reunidos en la encuesta, 2016.

Según la Unidad de planeamiento turístico, del total de turistas que ingresaron al país en el 2014, el 72,6\% se hospedaron al menos una noche en el Valle Central (ICT, 2015). Esta cifra indica que el Valle Central alberga la mayor cantidad de turistas internacionales en el país, y se relaciona con el hecho de que esta es la región en donde laboran la mayor cantidad de personas graduadas de Turismo Ecológico.

En este sentido, es importante indicar que; a pesar de que, la carrera de Turismo Ecológico se imparte en dos recintos del Valle Central: Paraíso y Grecia, la demanda de profesionales supera en un $12,7 \%$ a las personas formadas en ambos centros de educación superior. Por su parte, el Recinto de Golfito, ubicado en el Pacífico Sur, ha preparado tan solo el $4,1 \%$ de la totalidad de personas graduadas y emplea un total de $9,1 \%$ de profesionales; es decir, la región emplea más de un 5,0\% de profesionales que el mismo recinto no ha logrado graduar. En términos generales, el Valle Central como el Pacífico Sur ofrecen un mercado laboral atractivo, en el cual existen más puestos de trabajo que personas graduadas de las sedes o recintos de la UCR, lo que ha desencadenado que profesionales provenientes de otras unidades académicas busquen migrar hacia estas zonas en busca de empleo contribuyendo al desarrollo local con su profesión (ICT, 2016).

En la Figura 3, se indica la distribución de la población laboralmente activa según el tiempo servido a la empresa para la cual laboran en ese momento, de lo cual puede observarse que las personas encuestadas tienden a permanecer por más de dos y hasta por 
20 años en una misma empresa; sin embargo, es evidente que la mayor coincidencia se registró en personas con más de dos y menos diez años trabajando en un mismo lugar. Este dinamismo es menor cuando el profesional alcanzó los diez años brindando servicios de turismo $u$ otras actividades productivas.

Figura 3

Porcentaje de personas graduadas que laboran según el tiempo de trabajar para una empresa 0 institución, UCR-Costa Rica, 2016

$(n=251)$

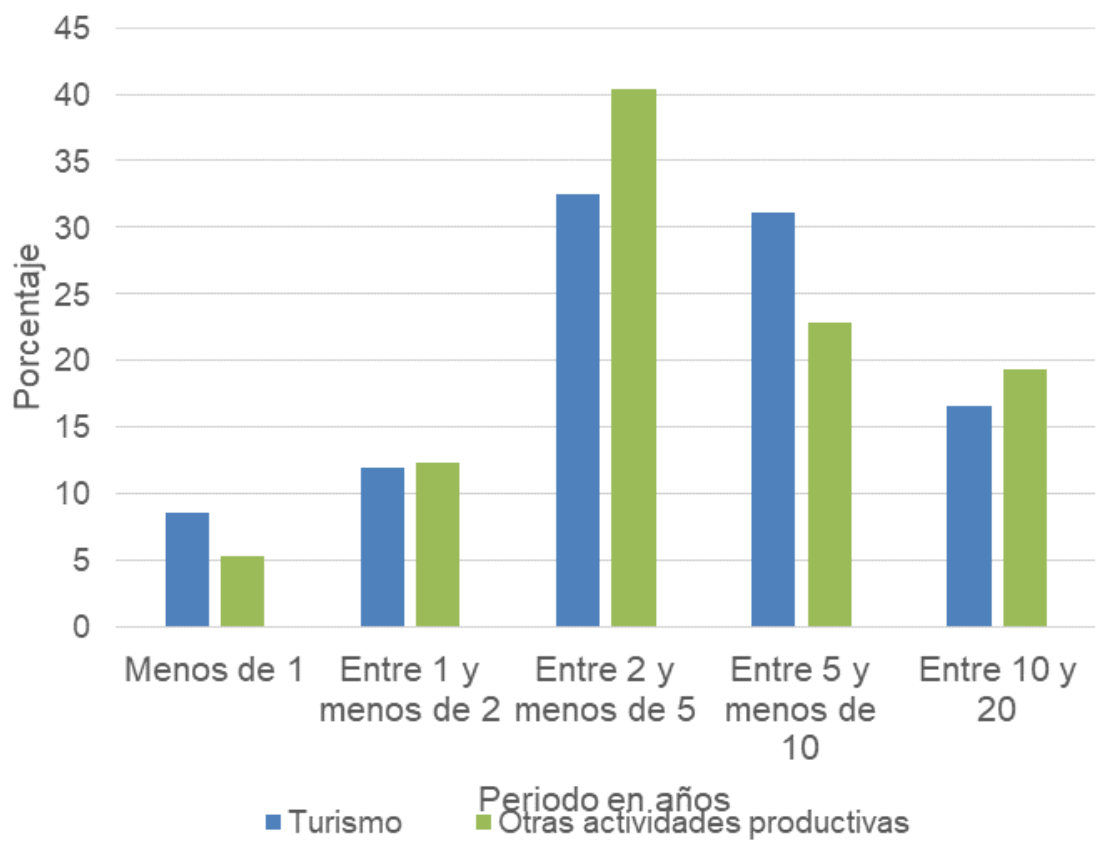

Fuente: Elaboración propia, con información de los datos reunidos en la encuesta, 2016.

En términos generales, el 82,9\% de las personas graduadas en Turismo Ecológico tienen entre 2 y 20 años de trabajar para una misma empresa, ya sea en su área de formación o mediante la complementación de su trabajo con otras actividades productivas, lo cual evidencia estabilidad laboral.

A pesar de que algunos autores como Marrero, Rodríguez y Ramos (2016) afirman que el empleo temporal es frecuente en el sector turístico, los datos obtenidos en esta investigación indican lo contrario y puede inferirse que las personas profesionales de Turismo Ecológico gozan de estabilidad laboral. Se debe recordar que el segundo gremio empleador de las personas profesionales en Turismo Ecológico es el estado, y que para Navarro y Selman (2014), la antigüedad en los cargos del sector público es muy superior en 
comparación con trabajadores del sector privado, lo que indica una menor rotación y mayor estabilidad.

En cuanto al grado de satisfacción con el empleo actual del profesional en turismo (Figura 4), las respuestas se evaluaron en una escala de entre 1 y 5 . En donde cinco es la mejor y uno la peor calificación.

Figura 4

Puntuación promedio de las personas graduadas según el nivel de satisfacción que tienen de su empleo, UCR-Costa Rica, 2016 ( $n=251$ )

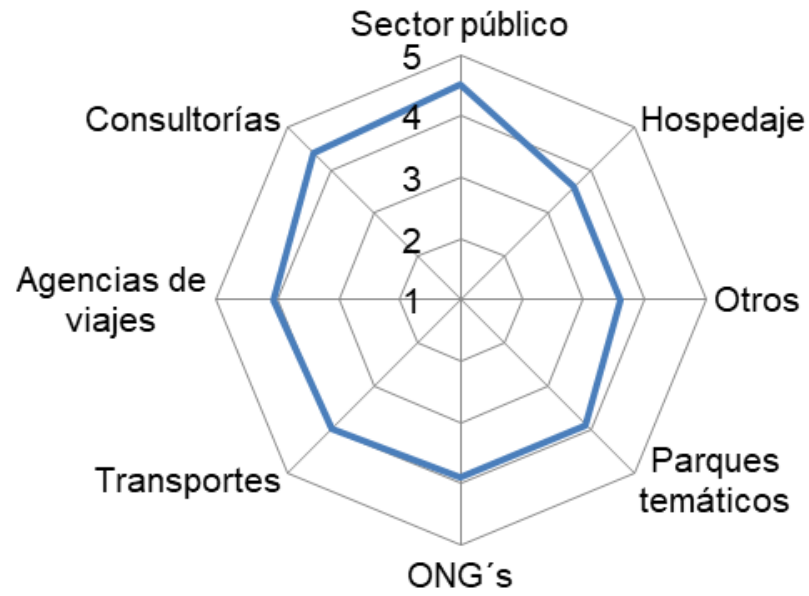

Fuente: Elaboración propia, con información de los datos reunidos en la encuesta, 2016.

La Figura 4 evidencia que en el sector público es donde las personas están más satisfechas, razón por la cual asignan una calificación de un 4,5. Muy de cerca las consultorías ofrecen un buen nivel de satisfacción a estas personas, quienes asignan una calificación de 4,4, y las agencias de viajes también reciben una calificación superior a 4,1. Son las personas que trabajan en las empresas hoteleras las que se encuentran menos satisfechas con su empleo.

Otro aspecto relacionado con la satisfacción laboral se relaciona de manera directa con la posición ocupacional como un importante indicio de mejores ingresos y/o mayor satisfacción laboral (Angulo et al., 2014). Un mayor nivel académico generalmente se asocia con mejoras salariales, por tanto, con un posgrado se obtendrán niveles laborales superiores que con un pregrado. En este sentido, la educación es un factor determinante en la 
satisfacción de las personas dentro del mercado laboral, al contribuir con el logro de mejores ingresos y un buen empleo (Angulo et al., 2014).

Los primeros años de vida laboral son un periodo de maduración y obtención de experiencia que le ayudarán al profesional en la consecución de mejores puestos de trabajo, dado el aprendizaje acumulado y la obtención de mejores niveles académicos. Para Martínez (2015), el uso de habilidades en el trabajo se traduce directamente en un aumento en la satisfacción, y esta a su vez deriva en un aumento de la motivación que dará como resultado final un mayor esfuerzo en las tareas, un mayor rendimiento y una mejor integración en la organización.

Angulo et al (2014) señalan que el tema de posición ocupacional es importante al ser indicio de mejores ingresos y/o mayor satisfacción laboral, y que por nivel académico hay mejoras salariales, por tanto, con un posgrado se obtendrán niveles laborales superiores que con un pregrado. De hecho; García (2004), menciona que la educación es un factor determinante en la satisfacción de las personas dentro del mercado laboral, al contribuir con el logro de mejores ingresos y un buen empleo.

La Figura 5 muestra los principales argumentos que manifestaron las personas profesionales que han tomado la decisión de laborar en otras actividades productivas diferentes al turismo. Las razones que exponen son: pocas garantías sociales que ofrecen las empresas turísticas $(45,6 \%)$, los puestos disponibles no satisfacen las expectativas $(36,8 \%)$, y los motivos personales $(36,8 \%)$. Aspectos como el trabajo temporal y la lejanía entre el lugar de trabajo y el de residencia son aspectos que alejan al graduado de la posibilidad de laborar según su formación. 
Figura 5

Porcentaje de personas graduadas según el motivo por cual se desempeñan en actividades productivas distintas al turismo, UCR-Costa Rica, $2016(n=251)$

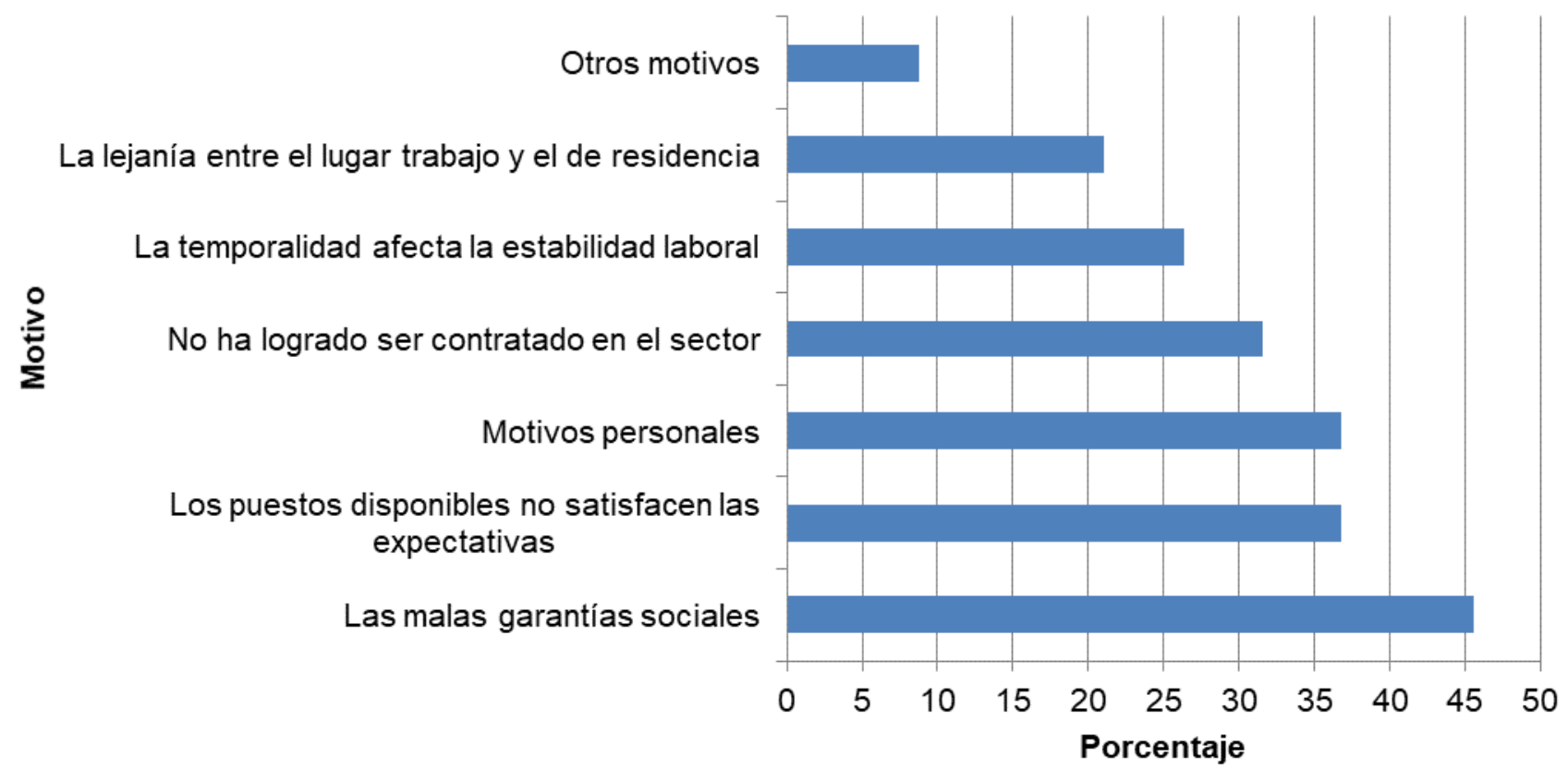

Fuente: Elaboración propia, con información de los datos reunidos en la encuesta, 2016.

Al profundizar sobre los motivos que pueden llevar a profesionales del área de turismo a laborar en otras actividades productivas, es importante indicar que en Costa Rica existen importantes leyes que obligan a las empresas a brindar garantías laborales para los trabajadores, sin embargo el cumplimiento de dichas obligaciones, a cabalidad, por parte del sector empresarial parece ser una debilidad en el turismo. Por ejemplo Mora y de Oliveira (2009), concluyeron que, en Costa Rica, poco más de la mitad (58.2\%) de la mano de obra asalariada de las empresas medianas labora en un puesto con algún nivel de precariedad, en las empresas grandes se trata de poco más de una tercera parte (36.4\%). En adición, Godínez (2008) manifestó que el 91,1\% de las inspecciones realizadas por el Ministerio de Trabajo y Seguridad Social de Costa Rica en el año 2005 culminaron con infracciones para las empresas empleadoras, así como que en el $68 \%$ de los casos la causa de dicha infracción fue el irrespeto a los derechos de las mujeres en condición de embarazo o lactancia materna. 
En la actualidad, la temporalidad y la precariedad son características de las nuevas contrataciones en el sector turismo, las cuales inciden directamente en la disminución de la motivación laboral, variable fundamental en la gestión de los recursos humanos debido a su impacto directo en la productividad (Martínez, 2015). Según Martínez (2015), la retribución económica ha dejado de ser el principal elemento motivador, y destaca incentivos no económicos muy valorados, como la flexibilidad, las medidas de conciliación, el desarrollo personal, la seguridad de las personas trabajadoras, el aumento de los beneficios sociales, mejorar la calidad de vida y que la organización verdaderamente practique los valores que predica.

Para OMT citada por (de Oliveira y da Silva, 2010) los empleos generados por el turismo poseen rasgos de inestabilidad y precariedad debido a la propia naturaleza del servicio prestado y la dependencia de factores externos no controlables, entre los que se pueden citar: el alto porcentaje de trabajadores temporales y ocasionales, un mayor número de horas semanales trabajadas, con horarios y turnos de trabajo especiales y un menor grado de sindicalización a otros sectores. Otro aspecto por considerar es que el movimiento de visitantes, en particular en el caso del turismo receptor, no está uniformemente distribuido a lo largo del año. Por lo tanto, el empleo en estas industrias variará estacionalmente, y con frecuencia su intensidad será más alta que en otras industrias (Naciones Unidas, Comisión de las Comunidades Europeas, Eurostat, OMT y Organización de Cooperación y Desarrollo Económicos, 2010).

En la Figura 6 se identifican las disciplinas que eligen las personas graduadas como bachilleres en turismo ecológico para continuar estudiando. La mayor predilección se da por el área de ecoturismo, la cual representa un 31\% de las escogencias. Administración de empresas y docencia, en conjunto, suman casi el $43 \%$ de los énfasis seleccionados, además las especialidades en desarrollo sostenible y manejo de recursos naturales entre otras, son de las áreas menos buscadas. 
Figura 6

Porcentaje de personas graduadas que continúan estudiando por la disciplina que cursan, UCR-Costa Rica, 2016 ( $n=251)$

\section{Manejo de recursos naturales

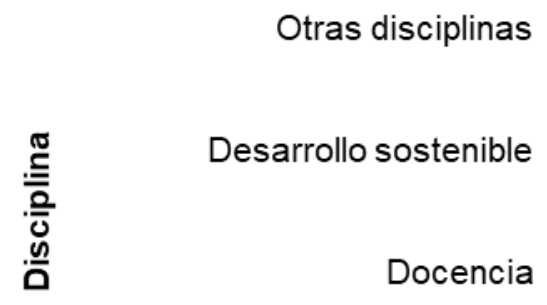

Administración de empresas

Ecoturismo

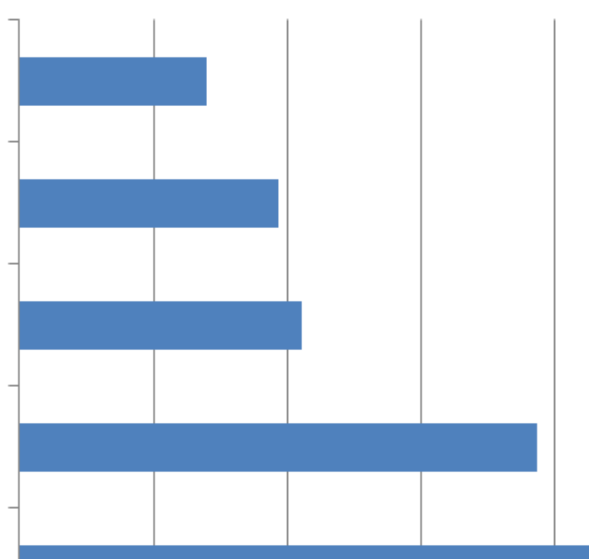

Fuente: Elaboración propia, con información de los datos reunidos en la encuesta (2016).

El $12,3 \%$ de las personas graduadas se dedican de manera exclusiva a estudiar. Además, se determinó que el 33,0\% de la población combina el trabajo y el estudio, este dato puede servir como un elemento orientador para construir distintas especialidades en el grado de licenciatura en el mediano plazo en la UCR. Asimismo, es un indicio de que las personas requieren aumentar los conocimientos o habilidades para lograr ocupar puestos laborales de mejor calidad o con mejores garantías laborales dentro el sector turismo.

A partir de los datos generados en la investigación, se puede indicar que la formación interdisciplinaria y transdisciplinaria de la carrera de Turismo Ecológico ha permitido la inserción laboral de las personas profesionales en otras actividades productivas cuando estos no logran ser contratados en el área específica de su formación, aspecto que evidencia la necesidad de fortalecer el vínculo con el sector empleador, en especial con las agencias de viajes, el hospedaje y el sector público que resultaron ser los principales gremios empleadores de estos profesionales. 
Las cifras reflejan un panorama cada vez más adverso para la población en el país y demuestra que el obtener un título universitario, no es necesariamente una garantía para encontrar empleo. La situación amerita cambios drásticos en el sistema de educación superior, mejores vínculos con el sector empleador y fijación de estrategias claras de desarrollo, entre otros aspectos. A pesar de que el INEC (2016) señala que el empleo decreció en un 1,7\% entre los años 2013 y 2014, e incrementó en un 3,4\% entre los años 2014 y 2015, durante el mismo periodo el turismo empleó en promedio a 150548 personas, la mayoría de ellas asignadas a los sectores de alimentos y bebidas seguido por el sector hospedaje.

\section{Conclusiones}

La investigación permitió conocer las principales características sociodemográficas y ocupacionales de las personas graduadas de la carrera de Turismo Ecológico de la UCR entre 1995 y 2014.

La mayor parte de la población de personas graduadas de la carrera de Turismo Ecológico se encuentra dentro de la llamada adultez emergente y presenta características típicas de esa etapa de desarrollo humano. Como elemento particular, se concluye que la mayoría de las personas graduadas son mujeres, así como que la mayoría de la población estudiada obtuvo su título en las sedes de Guanacaste, del Caribe y de Puntarenas.

Se determina que el $45,4 \%$ de la población graduada tiene la necesidad de continuar preparándose para afrontar su vida laboral, sin embargo, las posibilidades de cursar grados superiores a nivel de Licenciatura o Maestría son reducidas en la institución, ya sea por la lejanía entre los centros universitarios que ofrecen estas titulaciones o su lugar de residencia, por la poca diversidad de énfasis o bien por las dificultades de financiamiento de un posgrado, razones por las cuales el 47,5\% optó por ingresar a otras universidades, o bien por iniciar un nuevo Bachillerato en la misma universidad. Además, en otros casos, las personas prefieren combinar su trabajo con el estudio, condición que les puede permitir adquirir experiencia y recursos.

Apenas un 4,3\% de la población encuestada cuenta con el grado de Licenciatura 0 Maestría, lo que limita que puedan concursar por puestos de mayor calidad, así como que puedan tener un mayor impacto sobre el contexto turístico con sus acciones profesionales, enfocadas hacia el desarrollo sostenible. 
En cuanto al grupo de personas graduadas que forman parte de la población económicamente activa, se concluye que el nivel de desempleo es bajo en comparación con los indicadores nacionales, así como que, en su mayoría, de las personas se muestran satisfechas con su empleo actual y gozan de estabilidad laboral. No obstante, se concluye que existe una importante proporción de personas que ocupan puestos laborales que no guardan ninguna relación con su formación académica.

En cuanto a las posibilidades de conseguir empleo en turismo que este grupo de personas afronta, debe mencionarse que no son las mismas en las distintas regiones del país. De este modo, en Puntarenas y en el Caribe se encuentran las condiciones más adversas, mientras que Guanacaste y el Valle Central son las regiones que ofrecen mayor cantidad de puestos de trabajo. También se determinó que el Valle Central y el Pacífico Sur son las unidades de planeamiento turístico donde se ofrecen puestos de trabajo más atractivos, lo que ha movilizado a profesionales que han obtenido sus títulos en otras regiones del país hacia estos lugares.

Es evidente que un importante grupo de personas graduadas manifiesta haber laborado en empresas u organizaciones que no les han brindado las garantías laborales que la ley exige, así como que las formas de contratación y puestos de trabajo han sido una razón para buscar empleo en otras actividades productivas. Al respecto, se concluye que existe una necesidad de tener una mayor regulación por parte del Estado sobre el conjunto de empresas del sector turismo, así como que es necesario crear una organización que logre respaldar el quehacer profesional de estas personas.

La toma de decisiones respecto al manejo del plan de estudios de la carrera de Turismo Ecológico debe considerar las condiciones del conjunto de personas graduadas, de esa forma se podría responder en mejor medida a los compromisos que la universidad ha adquirido con la sociedad, asimismo, es urgente mejorar los vínculos con el sector empleador, propiciar novedosos canales de comunicación para fijar estrategias claras de desarrollo y retroalimentación. Por esto, se determina que el monitoreo de la situación que atraviesan este conjunto de profesionales debe realizarse de forma periódica, así como lograr mantener un vínculo que permita un acompañamiento y una retroalimentación real.

Una carrera no puede desarrollarse en sí misma, y en consecuencia incidir en su entorno, si a lo interno de su Alma Mater no se generan las rupturas necesarias de procedimientos, prácticas y políticas que le impiden evolucionar y superar su génesis. Debe permitírseles a las nuevas generaciones integrarse al cuerpo docente, contribuir en su 
actualización, búsqueda de excelencia académica, en fin, dotarla de recursos y darle la estabilidad.

\section{Referencias}

Angulo, Grace, Quejada, Raúl, y Yánez, Martha. (2014). Ingresos adecuados y satisfacción laboral: Análisis probabilístico basado en una encuesta a graduados de educación superior en Colombia. Trabajo y Sociedad: Indagaciones Sobre el Empleo, la Cultura y las Prácticas Políticas En Sociedades Segmentadas, (22), 141-160.

Arrieta, Giovanni, y Rivera, Gina. (2006). La carrera de Turismo Ecológico de la Sede de Guanacaste y el desarrollo del ecoturismo en la Universidad de Costa Rica. Intersedes, 7(13), 41-53.

Busso, Mariana, y Pérez, Pablo. (2015). Combinar trabajo y estudios superiores ¿Un privilegio de jóvenes de sectores de altos ingresos? Población y Sociedad, 22(1), 5-29.

Cerda, Rodrigo. (2016). Remuneraciones del sector público: mayores que en el sector privado. Estudios Públicos, (142), 7-35.

Comisión de Autoevaluación de Turismo Ecológico. (2013). Informe de autoevaluación del Bachillerato en Turismo Ecológico y Licenciatura en Gestión Ecoturística. Manuscrito inédito. San José, Costa Rica: UCR.

de Oliveira Matías, Karla, y da Silva Costa, Márcia. (2010). Políticas públicas para a geração de empregos: considerações sobre o proger turismo. Turismo: Visão E Ação, 12(1), 7391.

García, María. (2004). Efectos de la educación sobre los determinantes de la satisfacción laboral en España. Un análisis de los beneficios monetarios y no monetarios en el mercado de trabajo mediante modelos logit ordenados (Tesis doctoral). Universitat de València, Valencia, España. Tomado de la base de datos de Dialnet (No.7475).

García, Miriam. y Cárdenas, Elsa. (2018). La inserción laboral en la educación superior. La perspectiva latinoamericana. Educación XX1, 21(2).

Godínez, Alexander. (2008). La inspección de trabajo en Costa Rica, un balance de su gestión. Revista Latinoamericana de Derecho Social, 6, 3-27.

Gutiérrez, Ilse., Kikut, Lorena., Corrales, Karen., y Picado, Cinthya. (2018). Seguimiento de la condición laboral de las personas graduadas 2011-2013 de las universidades costarricenses (Informe № OPES-13/2018). San José, Costa Rica: CONARE.

Gutiérrez, Ilse., Kikut, Lorena., Navarro, Gustavo., Azofeifa, Cinthya. y Rodríguez, Nancy. (2015). Seguimiento de la condición laboral de las personas graduadas 2008-2010 de las universidades costarricenses (Informe N OPES-06/2015). San José, Costa Rica: CONARE. 
Hernández, Roberto., Fernández, Carlos. y Baptista, Pilar. (2014). Metodología de la investigación (6a. ed.). DF. México: Mc Graw Hill Education.

Instituto Costarricense de Turismo (ICT). (2002). Plan Nacional de Turismo Sostenible de Costa Rica 2002 - 2012. San José, Costa Rica: I.C.T.

Instituto Costarricense de Turismo (ICT). (2012). Plan Nacional de Turismo Sostenible de Costa Rica 2010 - 2016. San José, Costa Rica: I.C.T.

Instituto Costarricense de Turismo (ICT). (2015). Distribución de los pisos de demanda internacional según Unidad de Planeamiento Turístico 2014 (Todos los puertos). San José, Costa Rica: I.C.T. Recuperado de http://www.ict.go.cr/es/documentosinstitucionales/estad\%C3\%ADsticas/cifras-tur\%C3\%ADsticas/pisos-de-demanda/571-

$\underline{\text { 2014/file.html }}$

Instituto Costarricense de Turismo (ICT). (2016). Índice de Progreso social. San José, Costa Rica: I.C.T. Recuperado de http://www.ict.go.cr/es/estadisticas/cifras-turisticas.html

Instituto Nacional de Estadística y Censos (INEC). (2016). Encuesta Continua de Empleo (ECE). San José, Costa Rica: INEC.

Instituto Nacional de Estadística y Censos (INEC). (2017). Encuesta Continua de Empleo (ECE). San José, Costa Rica: INEC.

Instituto Nacional de Estadística y Censos (INEC). (2019). Encuesta Continua de Empleo al cuarto trimestre 2018. San José, Costa Rica: INEC.

Mankiw, Gregory. (2014). Macroeconomía. Barcelona, España: Antoni Bosh Editor.

Marrero, Rosa., Rodríguez, Pablo. y Ramos, José. (2016). La flexibilidad laboral en el sector turístico: Un análisis a partir de las ofertas de empleo. Estudios y perspectivas en turismo, 25(2), 143-163.

Martínez, José. (2015). Una Investigación sobre la motivación laboral en el sector turístico: implicaciones para la dirección de la empresa. TURyDES, 8(18), 1-17.

Mora, Mainor. y de Oliveira, Orlandina. (2009). La degradación del empleo asalariado en los albores del siglo XXI: Costa Rica y México. Papeles de Población, 15(61), 195-231.

Naciones Unidas, Comisión de las Comunidades Europeas, Eurostat, Organización Mundial del Turismo y Organización de Cooperación y Desarrollo Económicos. (2010). Cuenta satélite de turismo: Recomendaciones sobre el marco conceptual, 2008. Luxemburgo, Madrid, Nueva York y París. Recuperado de http://statistics.unwto.org/es/content/cstrmc2008

Navarro, Lucas. y Selman, Javiera. (2014). "Brechas salariales entre el sector público y privado en Chile: Evidencia a partir de datos longitudinales”. Revista Cepal, 112, 94110. 
Núñez, Luis, y Marín, Anyerline. (2018). La profesión de Turismo Ecológico en la Universidad de Costa Rica: Un análisis desde la perspectiva de su población graduada. Revista Educación, 42(2), 184-204.

Organización de las Naciones Unidas (ONU). (2015). Objetivos del Desarrollo del Milenio: Informe de 2015. New York, Estados Unidos: PBM Graphics.

Organización Mundial del Turismo (OMT). (2016). Barómetro del Turismo Mundial. Madrid, España.

Organización Mundial del Turismo (OMT). (2019). Barómetro del Turismo Mundial. Madrid, España.

Papalia, Diane, Feldman, Ruth, y Martorell, Gabriel. (2012). Desarrollo humano. México, D.F.: MCGraw-Hill.

Porter, Michael, Stern, Scott, y Green, Michael. (2017). Índice de progreso social 2017. Social Progress Imperative. Recuperado de http://www.incae.edu/images/descargables/CLACDS/ips2017/spi2017-informefinal2.pdf

Programa de las Naciones Unidas para el Desarrollo (PNUD). (2015). Informe sobre Desarrollo Humano 2015: Trabajo al servicio del desarrollo humano. San José, Costa Rica: PEN.

Programa Estado de la Nación (PEN). (2015). Quinto Informe: Estado de la Educación. San José, Costa Rica: PEN.

Programa Estado de la Nación (PEN). (2016a). Vigésimo Segundo Informe Estado de la Nación en Desarrollo Humano Sostenible. San José, Costa Rica: PEN.

Programa Estado de la Nación (PEN). (2016b). Quinto Informe Estado de la Región en Desarrollo Humano Sostenible. San José, Costa Rica: PEN.

Programa Estado de la Nación (PEN). (2017). Sexto Informe: Estado de la Educación. San José, Costa Rica: PEN.

Programa Estado de la Nación (PEN). (2018). Programa Estado de la Nación en Desarrollo Humano Sostenible. Informe Estado de la Nación 2018. San José, Costa Rica: PEN.

Quesada, Renato. (2006). Elementos del turismo. San José, Costa Rica: Editorial Universidad Estatal a Distancia.

Reglamento de empresas y actividades turísticas y sus reformas. (2013). Publicado en la gaceta N 101 del 28 de mayo de 2013. San José, Costa Rica: Imprenta Nacional.

Rodríguez Cid, Laura., Fraiz Brea, José-Antonio. y Ramos Valcárcel, David. (2015). Las Agencias de Viajes ante la influencia de las Redes Sociales en el turismo. El caso de Ourense. Pasos: Revista De Turismo Y Patrimonio Cultural, 13(4), 829-836. 
Samuelson, Paula. y Nordhaus William. (2014). Introducción a la macroeconomía. Madrid, España: MCGraw-Hill.

Universidad de Costa Rica (UCR). (1991). Apertura del Bachillerato en Turismo Ecológico. Universidad de Costa Rica, (Resolución N4880-90). San José, Costa Rica: UCR.

Universidad de Costa Rica (UCR). (2015). Reporte del Sistema de Aplicaciones Estudiantiles sobre estudiantes graduados de la carrera de Bachillerato en Turismo Ecológico y Licenciatura en Gestión Ecoturística. San José, Costa Rica: UCR. 


\section{Anexos}

Anexo 1. Variables e interrogantes utilizadas del cuestionario aplicado a las personas graduadas de Turismo Ecológico (2016).

\begin{tabular}{|c|c|}
\hline Variable & Prequnta \\
\hline $\begin{array}{l}\text { Características } \\
\text { sociodemográficas }\end{array}$ & 1. Edad, 2. Sexo, 3. Estado civil, 4. Lugar de residencia. \\
\hline $\begin{array}{l}\text { Estudios } \\
\text { académicos }\end{array}$ & $\begin{array}{l}\text { 5. ¿Cuál es el grado en Turismo Ecológico que obtuvo usted en la Universidad } \\
\text { de Costa Rica? } \\
\text { 6. ¿En cuál sede o recinto se graduó usted del Bachillerato en Turismo } \\
\text { Ecológico? } \\
\text { 7. ¿Cuánto tiempo tiene de haberse graduado de la carrera en Turismo } \\
\text { Ecológico? } \\
\text { 11. ¿Cuál es su grado académico actual? }\end{array}$ \\
\hline Ocupación & $\begin{array}{l}\text { 12. Con relación a su ocupación, actualmente usted: únicamente estudia, trabaja } \\
\text { y estudia, únicamente trabaja, no trabaja, ni estudia } \\
\text { 16. ¿En cuál unidad de planeamiento turístico se ubica la empresa o institución } \\
\text { para la cual usted trabaja? } \\
\text { 17. ¿La empresa o institución está vinculada al turismo? } \\
\text { 18. ¿En qué gremio del sector turismo se encuentra dicha empresa? } \\
\text { 19. ¿Cuál es la razón por la que no trabaja dentro del sector turístico? } \\
\text { 20. ¿A qué se dedica la empresa u organización para la que usted labora? } \\
\text { 21. ¿Cuál es el nombre de la organización en la que usted trabaja? } \\
\text { 22. ¿Cuál es el puesto trabajo que ocupa? Indique, en caso de que usted sea el } \\
\text { propietario. } \\
\text { 23. ¿Cuánto tiempo lleva trabajando en esta institución? } \\
\text { 25.En una escala de } 1-5 \text {, donde } 5 \text { es la mejor calificación y } 1 \text { la peor. ¿cuál es } \\
\text { el } \\
\text { satisfacción con su empleo actual? } \\
\text { 26. ¿Cuáles son los motivos por los cuales no estudia, ni trabaja? }\end{array}$ \\
\hline
\end{tabular}

$1 /$ La pregunta 20 aplicada a quienes manifestaron no trabajar en el sector turismo, mientras que la 26 para los que manifestaron no estudiar ni trabajar.

Fuente: Elaboración propia, con base en el cuestionario aplicado en la investigación, 2015. 
Revista indizada en
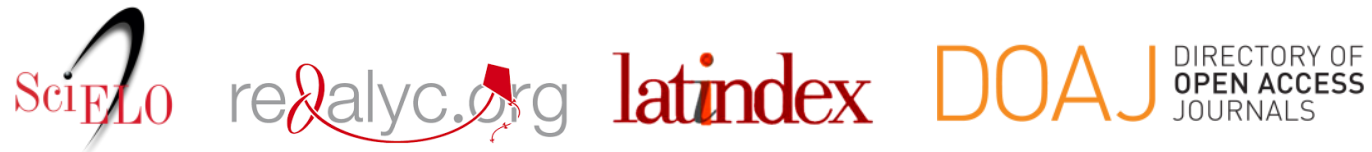

Distribuida en las bases de datos:

๑ Dialnet

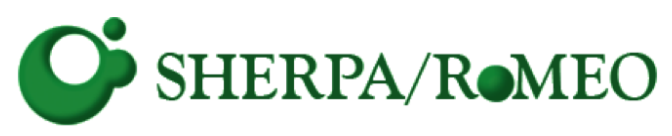

REDIB

Red Iberoamericana

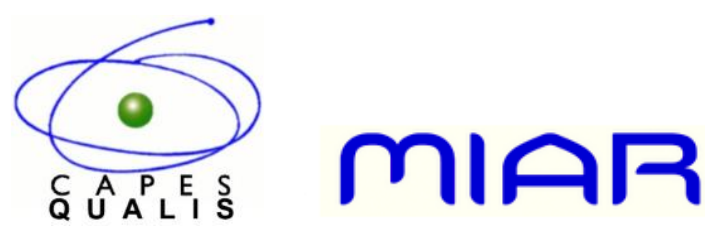

